\title{
INFORMACIONES
}

\section{ACTIVIDADES DE LOS INVESTIGADORES DE ENERO A DICIEMBRE DE 1986}

La doctora Clementina Díaz y de Ovando coordinó el Coloquio Hispano-Mexicano, Cinco Siglos de Intercambio México-España 1492-1992.

Asistió como ponente a varios congresos internacionales y nacionales entre otros: I Congreso Internacional sobre Lengua y Literatura Hispánicas en la época de los Reyes Católicos y el Descubrimiento. Pastrana, España. XI Coloquio de Historia del Arte del Instituto de Investigaciones Estéticas. México, D.F.

Impartió diversas conferencias sobre literatura del Siglo XIX. Continuó como miembro de la Comisión Dictaminadora del Instituto de Investigaciones Bibliográficas.

En noviembre terminó sus actividades como miembro de la Junta de Gobierno de la Universidad Nacional Autónoma de México.

Apareció publicado en coautoría con Luis Mario Schneider su libro: Arte culinario del siglo XIX, México, Fundación de Investigaciones Sociales, A. C. 1986.

Fue jurado del V Premio Literario Nezahualcoyotl. México, D.F., en noviembre. Organizado por el Instituto Cultural Domecq, A.C.

La doctora Elisa Vargas Lugo ingresó al Seminario de Cultura Mexicana, con un discurso sobre "La imagen del indio en el arte novohospino", el 10 de julio.

Dictó las siguientes conferencias: 8 de octubre, en Condumex, "Apuntes sobre la imagen del indio en el arte novohispano". El 30 de octubre, en la Casa de la Cultura, Qaxaca, Oax., "La pintura novohispana en Oaxaca". El 26 de noviembre, en la Escuela para Extranjeros, UNAM, "Arte Colonial en Yucatán". E1 2 de diciembre, en el Museo "Franz Mayer", durante el Ciclo organizado por la Delegación Cuauhtémoc, habló sobre "La Ciudad de México en el siglo XVIII".

Asistió a los siguientes congresos y mesas redondas; E1 10 de agosto, "Dos cultos nacionalistas en la Nueva España". Congreso Internacional de Historia del Arte. Washington, D.C. y el 12 de noviembre, "Iconografía de Santa Rosa de Lima en los virreinatos del Perú y de la Nueva Es- 
paña”. Ciudad Universitaria, XI Coloquio del Instituto de Investigaciones Estéticas.

Dirección de siete tesis: sobre arte novohispano: 1 de doctorado; 5 de maestría y 1 de licenciatura.

Viajes de estudio al interior del país, tomando fotografías para sus investigaciones y para aumentar el acervo de la fototeca, durante el año realizó diez viajes.

Hizo la defensa de monumentos, por medio de artículos y reuniones.

Tuvo a su cargo la organización de un curso sobre restauración de obras de arte, que se impartió en este Instituto, durante el mes de septiembre.

Prestó asesoría gratuita para el Premio "Rafael Heliodoro Valle".

Organizó la elaboración de Catálogo de Pii ituras del Museo del Carmen de San Ángel, con la colaboración de los alumnos de licenciatura de la Facultad de Filosofía y Letras y la Fototeca del Instituto de Investigaciones Estéticas.

Formó parte de la terna para la elección de director de este Instituto.

El profesor Xavier Moyssén formó parte de la Comisión editorial que se organizó por parte del señor Secretario de Educación Pública, para conmemorar el Primer Centenario del Nacimiento del pintor Diego Rivera, para la publicación de varios libros relacionados con su vida y su obra.

Invitado por The Detroit Institute of Arts, asistió en febrero 7 y 8, a la inauguración de la gran exposición retrospectiva que dicha institución organizó como Homenaje a Diego Rivera, dentro de los eventos conmemorativos del Primer Centenario de la Fundación de The Detroit Institute of Arts.

Durante el año dictó varias conferencias y formó parte de algunas mesas redondas, organizadas tanto por esta Universidad como por el Instituto Nacional de Bellas Artes, con motivo del Primer Centenario del nacimiento de Diego Rivera.

En el XI Coloquio de Historia del Arte organizado por este Instituto, el 14 de noviembre, presentó como ponencia el trabajo titulado " $\mathrm{El}$ mundo prehispánico y la conquista española en los murales de Rivera y Orozco".

El arquitecto Manuel González Galván, a nivel de posgrado, impartió la cátedra de arte colonial latinoamericano en la Facultad de Filosofía y 
Letras, así como de arte barroco en la de arquitectura de la UNAM. También dio dos cursos de arte colonial mexicano; uno en la Escuela de Restauración de Churubusco y otro en la Sala Sahagún del INAH, al cuerpo diplomático de damas, organizado por la Secretaría de Relaciones Exteriores.

Dictó las siguientes conferencias: "Retablos de la Nueva España", Poliforum INBA, Febrero 4. "El rostro oculto de la catedral de Oaxaca", Casa de la Cultura de Oaxaca, febrero 12. "Tipos de ciudades mexicanas", Planetarium de Morelia, junio 17. "Morelia porfiriana", Auditorio del Hospital Civil de Morelia, julio 16. "Grandeza artística de Morelia", Instituto Mexicano Norteamericano de Relaciones Culturales, septiembre 22. En la Sala Sahagún; "Urbanismo colonial", "Arquitectura civil del virreinato", y "La catedral de México", en octubre 6, 13 y 27.

Fue jurado de pintura en el Instituto Mexicano de Relaciones Culturales en enero 30.

Respondió las entrevistas: Periódico "La Voz de Michoacán"; sobre la catedral de Morelia, Febrero 5. Periódico "Noticias de Oaxaca"; sobre conservación de monumentos, febrero 19. En T.V., Canal 2, programa 24 horas; sobre Defensa del Tesoro Artístico de México, marzo 11. En T.V. Universitaria; sobre el XI Coloquio del IIE, septiembre 30.

Asistió al VI Simposyum de Conservación de Monumentos del ICOMOS, efectuado en Puebla del 8 al 12 de octubre con la ponencia "Reglamentos de construcción en centros históticos". En el XI Coloquio del IIE, realizado en México, D.F., el 14 de noviembre, intervino con la ponencia, "Castas y castidad del mexicano".

Con proyectos y asesoría suya, se inició y lleva a cabo, la restauración y remodelación de la catedral de Tacámbaro, Mich., dañada en el sismo de septiembre de 1985. También con su proyecto y dirección, se ejecuta, en la Basílica de Nuestra Señora de la Salud, en Pátzcuaro, el catafalco sepulcro de los restos de Don Vasco de Quiroga.

Recibió las siguientes distinciones honorificas: Diploma y medalla por veinticinco años de servicios académicos en la UNAM, mayo 15.

Presea José Tocavén, del periódico "La Voz de Michoacán", por la defensa de la arquitectura de la ciudad de Morelia, junio 19.

Presea "Al mérito profesional", como ex-alumno distinguido del Colegio Valladolid de la ciudad de Morelia, junio 19.

La doctora Beatriz de la Fuente impartió durante el primer semestre su Seminario de Investigación y Tesis de Arte Prehispánico, en la Di- 
visión de Estudios de Posgrado de la Facultad de Filosofía y Letras de la UNAM.

Fue designada Landsdowne Professor de la University of Victoria, Canadá, donde impartió el curso Images in Precolumbian Sculpture, del 10 al 20 de enero.

Participó como ponente en: El Simposio sobre Diego Rivera en el Detroit Institut of Arts, en Detroit, Michigan, con la ponencia Diego Rivera and Precolumbian Art, el 8 de febrero. El Congreso sobre El humanismo en México en vísperas del siglo XXI, organizado por la Coordinación de Humanidades de la UNAM, en el Auditorio de la Cueva, con la ponencia "El humanismo y el arte", el 22 de abril. El XXVI International Congress of Art History, en Georgetown University, Washington, D.C. con la ponencia Sacred plants and men in precolumbian art, el 14 de agosto. E1 Simposio Diego Rivera Hoy, organizado por el Instituto Nacional de Bellas Artes, en la sala Manuel M. Ponce del Palacio de Bellas Artes, México, con la ponencia "El arte prehispánico y la pintura mural de Diego Rivera", el 26 de agosto.

Dictó su curso, como miembro de El Colegio Nacional, del 2 al 10 de septiembre, en el edificio sede de dicho Colegio, con el tema La escultura en Mesoamérica: de la expansión olmeca al florecimiento maya clásico: "El estilo escultórico olmeca: su difusión en el espacio y el tiempo", el día 2: "La escultura maya clásica: rasgos generales y estilos regionales. Técnicas y temas. Su evolución", el día 4; "La escultura en Tikal. Forma y significado. Su evolución", el 8; "La escultura en Palenque. Forma y sig. nificado. Su evolución", el día 10.

Sustentó las siguientes conferencias: "Técnicas, modos, materiales y significados en la escultura prehispánica", en el Colegio de Historia de la Facultad de Filosofía y Letras de la UNAM, el 13 de mayo; "Grandes Temas, Grandes Maestros", en la Escuela Nacional Preparatoria de la UNAM, el 25 de junio; "La figura femenina en la plástica prehispánica" dentro de la serie "Temas selectos de Arte Prehispánico", organizada por El Colegio Nacional, la Dirección de Extensión Académica y el Instituto de Investigaciones Estéticas de la UNAM, el 2 de julio; "Nueva visión de la escultura olmeca monumental", en la Escuela de Antropología de la Universidad Veracruzana en Xalapa, Veracruz, el 18 de julio; "En torno a la figura humana en la escultura maya", en la Academia Nacional de Medicina, el 22 de septiembre.

Fue reelecta a la Vicepresidencia del Comité International d'Histoire de l'Art, durante el XXVI International Congress of Art History celebrado en Washington, D. C., el 15 de agosto. 
Organizó, como directora del Instituto de Investigaciones Estéticas, en colaboración con la doctora Elisa García Barragán, Secretaria Académica, el XI Coloquio Internacional de Historia del Arte, con el tema: "Historia, Leyendas y Mitos de México: su expresión en el arte", en el Auditorio de la Biblioteca Nacional de la UNAM, del 10 al 15 de noviembre.

Rindió su informe acerca de las actividades del Instituto de Investigaciones Estéticas del 28 de noviembre de 1980, al 28 de noviembre de 1986, al término de su gestión como Directora del Instituto.

La doctora Elisa García Barragán asistió al Coloquio: Cinco Siglos de Intercambio México-España 1492-1992, efectuado en el Palacio de Minería, México, D. F., durante la VI Feria Internacional del libro. Su ponencia se tituló: "Juan Suárez de Peralta. Referencias del ámbito geográfico novoshispano".

Fue invitada como oradora especial por la Texas Association of Museums a su Anual Meeting and Trustees Conference: Bridges from the past cultural legacies for the future, que tuvo lugar el 3 de abril en Galveston, Texas. Su ponencia se tituló: "Cultural legacies between Mexico and Texas and responsability of museums to serve our pluralistic society".

También asistió al I Congreso Internacional sobre Lengua y Literatura Hispánica en la época de los Reyes Católicos y el Descubrimiento, celebrado en Madrid y Pastrana del 5 al 8 de julio, presentando la ponencia: "Juan Suárez de Peralta. Trasuntos medievales en la crónica renacentista".

Colaboró con la doctora Beatriz de la Fuente en la organización del XI Coloquio Internacional de Historia del Arte del Instituto de Investigaciones Estéticas, cuyo tema fue: "Historia, Leyendas y Mitos de México: Su expresión en el arte", mismo que se llevó a cabo del 10 al 14 de noviembre en el Auditorio de la Biblioteca Nacional de la UNAM.

Presentó los libros: Peldaños en la conciencia. Rostros en la plástica prehispánica de Beatriz de la Fuente, y Fémina Danza de Alberto Dallal el día 9 de marzo, durante la VI Feria Internacional del Libro, en el Palacio de Minería.

Invitada por la Universidad Autónoma de Sinaloa, participó como jurado del Concurso de Escultura, Pintura y Grabado del X Salón de la Plástica Sinaloense y del Premio del Noroeste, que tuvo lugar en Culiacán, Sinaloa, el 12 de agosto.

En la Escuela Nacional de Pintura y Escultura "La Esmeralda", dictó varias conferencias sobre Muralismo Mexicano, Siglos XIX y XX y sobre 
el pintor Diego Rivera, en colaboración con la Coordinaciớn de Extensión Académica de la UNAM, en San Ildefonso y el Auditorio de la Biblioteca Nacional de la UNAM y en la Escuela Nacional de Artes Plásticas de la UNAM.

Publicó, en coautoría con Luis Mario Schneider, el libro Diego Rivera y los escritores mexicanos. Antología Tributaria. México, UNAM, Instituto de Investigaciones Bibliográficas, 1986.

Fue nombrada directora del Instituto de Investigaciones Estéticas por la Junta de Gobierno de la UNAM el día 8 de diciembre de 1986; ocupa dicho cargo desde el 9 de diciembre del mismo año.

El maestro Marco Díaz fue nombrado curador de la exposición Gabriel Guerra. Una voluntad escultórica, presentada por el Museo Nacional de Artes el mes de mayo.

Dictó dos conferencias: "De arte y bibliotecas" en la Universidad Autónoma de Puebla, e "Itinerarios barrocos en Talxcala", en la Universidad Autónoma de Tlaxcala, en los meses de mayo y septiembre respectivamente. Presentó la ponencia "Características del barroco en Tlaxcala" en el Simposio sobre Estudios en Tlaxcala, celebrado en julio.

Fungió como asesor en el Instituto Tlaxcalteca de Cultura y en la Pinacoteca de la Universidad Autónoma de Puebla.

Asistió al Coloquio Internacional de Historia del Arte, celebrado en la ciudad de México, organizado por este Instituto.

El maestro Alberto Dallal participó como miembro de la Comisión Dictaminadora de la División de Estudios de Posgrado de la Escuela Nacional de Artes Plásticas (hasta noviembre) y de la Comisión Organizadora del XI Coloquio Internacional de Historia del Arte del Instituto de Investigaciones Estêticas (hasta junio).

Impartió el curso "Los géneros periodísticos y las actividades del arte y la cultura" y dictó una conferencia, "La danza en México" en Monterrey, Nuevo León (mayo). Dictó dos conferencias sobre "Arte tradicional y arte contemporáneo" en la sede del Ballet Nacional de México (julio) y otra en torno de "La política y la cultura en México: periodismo, literatura y política internacional" en la Universidad de las Américas, Cholula, Puebla (octubre). 
En octubre-noviembre asistió como observador y crítico al encuentro de Danzantes Indígenas de Tabasco y al Décimo Festival Internacional de Ballet de La Habana, Cuba. Presentó la ponencia "El estudio de la religiosidad en las danzas indígenas" durante el Primer Encuentro de Investigación de Música y Danza Indígenas de Villiahermosa, Tabasco (octubre), y la ponencia "Interacción de las políticas culturales interna y externa" durante el Primer Congreso Nacional de la Asociación Mexicana de Estudios Internacionales (Anfitrión: Universidad Autónoma de Querétaro, noviembre). Fue miembro del jurado en el XIV Concurso Estatal de Cuento de la Universidad de Sonora y participó como entrevistador y conferenciante en los homenajes al coreógrafo Luis Fandino con motivo de sus treinta y cinco años de trabajos profesionales ininterrumpidos (Sala Manuel M. Ponce y Teatro de la Danza del INBA, noviembre).

La SEP publicó 30,000 ejemplares de: El "dancing" mexicano; en Lecturas Mexicanas No. 70. 2a. serie. 1986. 208 pp. más ilustraciones.

$*$

El doctor Aurelio de los Reyes asistió con la ponencia "Nacimiento de un mito: Dolores del Río", al XI Coloquio de Historia del Arte del Instituto de Investigaciones Estéticas el mes de noviembre.

Participó con la ponencia "Novela, cine y literatura", al VIII Coloquio de Antropología e Historia Regionales, sobre el nacionalismo mexicano, organizado por el Colegio de Michoacán, en Zamora, durante el mes de octubre.

Impartió la conferencia "Primeros años de cine en México", el 21 de agosto en la Filmoteca de la UNAM.

Dictó la conferencia "Investigación y docencia" el 12 de agosto, en la Facultad de Filosofía y Letras, en el Colegio de Historia.

Impartió el curso "Antecedentes históricos del cine mexicano", del 12 al 16 de mayo dentro del programa de cursos para la actualización de pro fesores de posgrado de ciencias sociales, de la Universidad Autónoma Metropolitana, plantel Azcapotzalco.

Dirigió un seminario de avance de la investigación, el mes de noviembre en el Departamento de Historia de la Universidad Iberoamericana.

Fue nombrado asesor del Departamento de Historia del Arte, de la División de Estudios de Posgrado de la Facultad de Filosofía y Letras, a partir del 7 de mayo.

Realizó la traducción del estudio preliminar (Con Villa en México) de su libro: (With Villa in Mexico) para el anuario de la Biblioteca del Congreso. 
Durante el año de 1986 la maestra Martha Fernández escribió un total de treinta y dos artículos en defensa del patrimonio nacional, publicados en las secciones "La cultura al día" y "El Búho" del periódico Excélsior, entre los que destacan: "Un robo nada sorpresivo: 'apego' a nuestros valores", "Sucio e indeseable ejemplo: la casa de González Bocanegra", "La "vasija del Monito': ¿sólo en la memoria?", "E1 Universalismo de México", "Proyecto esperanzador: salvemos al Centro" e "Increíble despojo al convento de Guadalupe".

Asimismo, asistió a las I Jornadas pro-conservación del patrimonio histórico y artístico, de la Delegación Cuauhtémoc en las que presentó la ponencia titulada "Monumentos de los siglos XVI y XVII en el Centro Histórico de la Ciudad de México: la ruta de Francisco Cervantes de Salazar", el día 2 de diciembre. Asistió también al XI Coloquio Internacional de Historia del Arte, organizado por el Instituto de Investigaciones Estéticas del 10 al 14 de noviembre bajo el tema: "Historia, leyendas y mitos de México: su expresión en el arte".

El 28 de mayo la Mtra. Martha Fernández ingresó a la Sociedad Defensora del Tesoro Artístico de México.

El doctor José Guadalupe Victoria Vicencio, quien gozó de su periodo sabático de enero a agosto, continuó su investigación sobre el pintor Baltasar de Echave Orio e inició dos más: una acerca de La Arquitectura de los Agustinos en la Nueva España y otra sobre Los santuarios de la ciudad de México en el siglo XVIII.

Participó en el Primer Coloquio de Historia Regional, celebrado en la ciudad de Pachuca, Hgo. (20 a 24 de enero), con una ponencia titulada: Retablística Novohispana en el Estado de Hidalgo, y en el XI Coloquio Internacional de Historia del Arte, del Instituto de Investigaciones Estéticas, con un trabajo titulado: De Blasones y Baluartes Mexicanos: los santuarios de la ciudad de México en el siglo XVIII.

Continuó su trabajo docente en la División de Estudios de Posgrado de la Facultad de Filosofía y Letras de la UNAM, donde imparte un Seminario Monográfico de Arte Colonial. Impartió un curso de Teoría de la Arquitectura en el Instituto Tecnológico de Monterrey, Unidad Querétaro (eneromayo). En el Departamento de Historia del Arte de la Universidad Iberoamericana tuvo a su cargo el Seminario de Investigación y Tesis (agosto- 
diciembre). Coordinó e impartió dos cursos organizados por la Dirección de Proyectos Académicos de la Secretaría General de la UNAM: Entre Fantasía y Realidad: la enseñanza de la historia del arte y Arquitecturas deslumbrantes.

Realizó una visita a la ciudad de Taxco, Gro., con el Curso Vivo de Arte de la UNAM.

El maestro Rogelio Ruiz Gomar participó en el "Inventario histórico y cultural de la Catedral de México" que se realizó dentro de los proyectos de la Secretaría de Desarrollo Urbano y Ecología (SEDUE), ocupándose de elaborar los textos y fichas técnicas correspondientes a la "Capilla de los Reyes", "Altar del Perdón”, "Capilla de los santos Cosme y Damián” y "Sagrario Metropolitano".

Se encargó del estudio de "Las colecciones de pintura del museo Regional de Querétaro", para el volumen que, por iniciativa del Gobierno de dicha entidad federativa, se preparó para conmerorat los 50 años de vida de ese museo.

Sustentó cuatro conferencias, entre las que cabe destacar la que se verificó en el Polyforum Cultural Siqueiros sobre "La pintura novohispana de los siglos XVII y XVIII", enero 21, y la que dictó sobre "La colección de pintura del Museo Regional de Querétaro", en el auditorio del propio museo, noviembre 7.

Preparó el "Guión museográfico" y la selección de los cuadros para una exposición sobre "La pintura en la Nueva España", por encargo del Centro Cultural Contemporáneo. Fungió como asesor en los trabajos que se llevaron a cabo para la reapertura de la Pinacoteca Virreinal de San Diego (INBA, México, D. F.) y participó en la selección de las piezas para el Museo de la Catedral de México.

Llevó ocho visitas guiadas (Catedral de México, Azcapotzalco, San Ângel, Huejotzingo, Taxco y Zacatecas), las más de ellas dentro del programa de "Paseos culturales" del INAH.

La doctora Clara Bargellini participó en el Primer Coloquio de Historia Regional de Pachuca, Hidalgo, en enero. Durante marzo y abril estuvo en Florencia, Italia, donde trabajó sobre problemas de la historia del gusto, en I Tatti y en el Kunsthistorisches Institut. Esa investigación resultó en 
una ponencia para el XI Coloquio del Instituto de Investigaciones Estéticas en noviembre. También hizo un viaje de estudio a varios sitios del estado de Zacatecas, para finalizar su trabajo sobre la arquitectura colonial del centro norte.

El doctor Gustavo Curiel participó en la elaboración de los comentarios artísticos del libro: Estado de Guanajuato; Cuatro Monumentos del Patri. monio Cultural, editado por la Secretaría de Desarrollo Urbano y Ecología.

Participó en el libro: La Catedral de México; patrimonio artístico y cul. tural, editado por la Secretaría de Desarrollo Urbano y Ecología, con el texto e inventario de las capillas de San Miguel, Virgen de las Angustias de Granada y San Felipe de Jesús.

Asesoró a la Dirección de Monumentos Coloniales del Instituto Nacional de Antropología e Historia, en el proyecto de fundamentación teórica para la elaboración del reglamento de uso del Centro Histórico de la ciudad de México.

Obtuvo su definitividad como Profesor de Asignatura "A" del Seminario de Arte Colonial, que se imparte en la Facultad de Filosofía y Letras de la UNAM.

Tomó parte en el ciclo de conferencias "Nueva Visión de la Pintura Colonial Mexicana", organizado por la Pinacoteca Virreinal y el Instituto de Investigaciones Estéticas de la UNAM, con la conferencia: La pintura profana en la Nueva España.

Participó en el ciclo de mesas redondas y conferencias: "Jornadas proconservación del Patrimonio Cultural de la Delegación Cuauhtémoc", organizado por la Delegación Cuauhtémoc y el Museo Franz Mayer, con la conferencia: Degradación del Patrimonio Cultural. Diciembre 1986.

En el XI Coloquio Internacional de Historia del Arte, organizado por este Instituto, presentó la ponencia: "San Felipe de Jesús: figura y culto (1629-1682)", el 11 de noviembre de 1986.

Fue nombrado miembro del Comité Mexicano de Historia del Arte y, asimismo, de la Sociedad Defensora del Tesoro Artístico.

La doctora Elia Espinosa en colaboración con el Departamento de Ex. tensión Académica de la UNAM, llevó las siguientes visitas guiadas: 9 de 
octubre: frescos de Diego Rivera en el Palacio Nacional; 16 de octubre: frescos de José Clemente Orozco en el Colegio de San Ildefonso; 10. de diciembre: Colegio de San Ildefonso: su historia, su arquitectura; 5 de diciembre: Palacio Nacional: su historia, su arquitectura.

Miembro de la Comisión Organizadora del XI Coloquio Internacional de Historia del Arte del Instituto de Investigaciones Estéticas, celebrado del 10 al 14 de noviembre.

El 14 de noviembre presentó la ponencia: Lo cursi y los elementos que lo transforman en la pintura de Jesús Helguera, en el XI Coloquio Internacional de Historia del Arte, organizado por este Instituto. En programa especial de la Televisión Universitaria, hizo la presentación del Coloquio. Impartió un curso de introducción a la Historia del Arte, a alumnos de la carrera de Bibliotecología, en la Facultad de Filosofía y Letras de la UNAM.

La maestra Louise Noelle Mereles obtuvo el nombramiento como Investigador Ordinario Asociado "A", en el mes de octubre, en la especialidad de Arquitectura Contemporánea Mexicana. Asimismo fue nombrada cronista de la Academia de Arquitectura, Sociedad de Arquitectos Mexicanos, en enero.

Colaboró con artículos especializados para las revistas Anales del Instituto de Investigaciones Estéticas, Arquitectura y Sociedad y Obras de Méxixico; L'architettura, cronache e storia, de Italia, y Batlía de España. También editó las memorias del Coloquio Internacional de Historia del Arte sobre "Arte funerario". Realizó dos visitas guiadas a murales de Diego Rivera, dentro de las actividades para celebrar el Centenario de su nacimiento. Dictó varias conferencias y participó en mesas redondas.

Asistió al XI Coloquio del Instituto de Investigaciones Estéticas, realizando un comentario a la ponencia del maestro Fausto Ramírez: "Dioses, héroes y reyes mexicanos en el París del 1883". 